Article

\title{
New Feedstock System for Fused Filament Fabrication of Sintered Alumina Parts
}

\author{
Dorit Nötzel ${ }^{1,2}$ and Thomas Hanemann ${ }^{1,2, * \mathbb{D}}$ \\ 1 Karlsruhe Institute of Technology, Institute for Applied Materials, Hermann-von-Helmholtz-Platz 1, \\ 76344 Eggenstein-Leopoldshafen, Germany; dorit.noetzel@kit.edu \\ 2 Department of Microsystems Engineering, University Freiburg, Georges-Köhler-Allee 101, \\ 79110 Freiburg, Germany \\ * Correspondence: thomas.hanemann@kit.edu; Tel.: +49-721-608-22585
}

Received: 11 September 2020; Accepted: 30 September 2020; Published: 8 October 2020

check for updates

\begin{abstract}
Only a few 3D-printing techniques are able to process ceramic materials and exploit successfully the capabilities of additive manufacturing of sintered ceramic parts. In this work, a new two component binder system, consisting of polyethyleneglycol and polyvinylbutyral, as well stearic acid as surfactant, was filled with submicron sized alumina up to $55 \mathrm{vol} \%$ and used in fused filament fabrication (FFF) for the first time. The whole process chain, as established in powder injection molding of ceramic parts, starting with material selection, compounding, measurement of shear rate and temperature dependent flow behavior, filament fabrication, as well as FFF printing. A combination of solvent pre-debinding with thermal debinding and sintering at a reduced maximum temperature due to the submicron sized alumina and the related enhanced sinter activity, enabled the realization of alumina parts with complex shape and sinter densities around $98 \%$ Th. Finally the overall shrinkage of the printed parts were compared with similar ones obtained by micro ceramic injection molding.
\end{abstract}

Keywords: fused filament fabrication; 3D Printing; FFF/FDM; composites; ceramics; alumina

\section{Introduction}

Over recent years, a huge variety of additive manufacturing (3D printing) methods have been developed, starting with polymer materials and extended nowadays to ceramics, metals, composites, or other advanced functional materials. Actually, the inclusion of time as a fourth dimension has been started and is denoted as 4D Printing [1-6]. 3D printing allows the realization of "impossible" parts with particular geometrical features, which cannot be produced applying established fabrication methods. Related to material processing, 3D printing can be distinguished in seven categories, namely material extrusion, material jetting, binder jetting, powder bed fusion, direct energy deposition, vat polymerization, and sheet lamination [7]. Originally, most of these were used for the processing of polymer-based materials, like UV-curable reactive resins in case of vat polymerization (Stereolithography, SLA) or thermoplastics in the case of extrusion (Fused Filament Fabrication, FFF). Comprehensive material research in close cooperation with machine technology development enabled, that SLA and FFF can be used recently for the realization of functional composites e.g., with piezoelectric, conductive, ferroelectric, or magnetic properties [8-12]. Whilst metal parts are mainly printed directly by the different variants of Selective Laser Sintering (SLS), Selective Laser Melting (SLM), or quite recently by Electron Beam Melting (EBM) [13-16], ceramic parts can be printed via SLA and FFF using highly filled low viscous resins (SLA) or molten thermoplastics (FFF). In the case of SLA, this technology has been commercialized (Lithoz GmbH, Vienna, Austria, www.lithoz.com), recent research can be found in [17-22]. The fabrication of ceramic or metallic parts by FFF has the major advantage that experience derived from powder injection molding (PIM) helps to develop 
highly filled feedstocks (ceramic: $>45$ vol. $\%$, metal: $>60$ vol. $\%$ solid load) with a similar binder composition [23,24]. Considering only ceramics, up to now mostly sintered alumina or mullite [23-26], zirconia [27-29], or silicon nitride [30] parts have been realized, typical binder components are paraffin wax, (modified) polyolefines, or thermoplastic elastomers. Fatty-acid derivatives, like stearic acid, or commercial additives with proprietary composition, are widely established as surfactants or plasticizers [23-25,27,28,30,31]. Like feedstocks in ceramic injection molding, two component binder mixtures are often applied, one low molecular mass material allows a low melt viscosity at moderate temperatures and one high molecular mass fraction (backbone polymer) delivers a certain mechanical stability at lower temperatures after shaping. The low molecular mass compound can be removed during an organic solvent pre-debinding step after printing, e.g., in hexane [23,24] or cyclohexane [28]. In micro ceramic injection molding, new binder systems avoiding the necessity to use organic solvents for pre-debinding have been developed. Polyvinylbutyral (PVB) or polymethylmethacrylate (PMMA) as backbone polymer and polyethyleneglycol (PEG) as low molecular mass component were successfully tested with ceramic and metal fillers [32-34], even the usage of by FFF or PolyJet ${ }^{\circledR}$ (3D Inkjet) printed mold inserts was possible [35]. After replication and during debinding, the low molecular binder component PEG can be dissolved in cold water instead of the highly flammable hexane at $50{ }^{\circ} \mathrm{C}$.

This work describes the first-time implementation of the PEG/PVB binder system as ceramic filler carrier in ceramic FFF 3D printing. The realization and structural characterization of complex alumina parts will be presented in detail.

\section{Materials and Methods}

Regarding the realization of dense ceramic parts via FFF a process chain analogous to injection molding was developed. This was successfully demonstrated earlier applying a binder system consisting of wax and polyethylene [23,24] covering the following steps:

1. Material (filler, binder, and surfactant) selection;

2. Compounding and rheological characterization;

3. Filament extrusion;

4. Feedstock printing; and

5. Thermal post-processing (debinding, sintering)

For each step, a comprehensive material characterization has to be investigated with respect to develop a robust process chain enabling dense and warpage-free ceramic parts.

\subsection{Material Selection}

As in previous work-FFF and micro injection molding [23,36] —a submicron sized alumina $\left(\mathrm{Al}_{2} \mathrm{O}_{3}{ }^{\prime}\right.$ TM-DAR, Taimai Chemicals, Tokyo, Japan) was selected as ceramic because of its huge sinter activity enabling density values better than $99 \%$ at moderate sinter temperatures $\left(1400{ }^{\circ} \mathrm{C}\right)$ [37]. The measured average particle size $d_{50}$ is around $0.1 \mu \mathrm{m}$, the specific surface value, measured via the BET (Brunauer-Emmett-Teller) method, is $11.8 \mathrm{~m}^{2} / \mathrm{g}$ [23]. In contrast to the established binder system, wax/polyethylene in powder injection molding used for alumina, zirconia, tungsten, and stainless steel $[38,39]$, a partially water-soluble binder will be applied. Polyvinylbutyral (PVB, Mowital B30H, Kuraray Europe GmbH, Hattersheim/Main, Germany) was used as backbone polymer (glass transition temperature $68^{\circ} \mathrm{C}$, melting temperature $135-170{ }^{\circ} \mathrm{C}$ ) delivering a certain mechanical stability at lower temperatures. Polyethyleneglycol (PEG 4000, Roth GmbH, Karlsruhe, Germany) was selected as low molecular weight plasticizer (softening temperature $53-58{ }^{\circ} \mathrm{C}$ ) enabling a reduced viscosity during compounding. To achieve a reliable coupling between the hydrophilic ceramic and the hydrophobic polymer matrix, stearic acid (SA, Roth GmbH, Karlsruhe, Germany) was chosen as surfactant guaranteeing a low feedstock viscosity and good homogeneity in the molten state. The SA concentration was set to $3.3 \mathrm{mg} / \mathrm{m}^{2}$ referred to the alumina's specific surface area 
guaranteeing a complete ceramic particle surface coverage [36]. The surface profile (2D and line scans) were measured applying a white light interferometer (Micro Prof ${ }^{\circledR}$ 100, Fries Research Technology, Bergisch Gladbach, Germany).

\subsection{Compounding and Rheological Characterization}

All feedstocks have been prepared in a mixer-kneader compounder (W50-EHT, Brabender, Duisburg, Germany) which allows for torque recording during mixing. The compounding temperature was set to $110{ }^{\circ} \mathrm{C}$, the mixing time to 60 min guaranteeing the formation of a homogeneous feedstock. To ensure an operator independent processing, a fixed sequence of the addition of the individual components was defined: First, approximately $20 \%$ of the alumina was filled in the mixing chamber (volume around $45 \mathrm{~mL}$ ). Second, the surfactant was added enabling an improved surface coverage and prior to the polar binder parts, which also can bind via physisorption to the ceramic. Third, the premixed PEG/PVB was adjoined and the remaining filler was placed in the mixing chamber finally. A typical torque vs. time compounding curve can be seen in [23] for a similar highly filled composite applying a wax-polyethylene binder system. The shear rate and temperature dependent flow properties have been measured by high pressure viscosimetry using a Rheograph 25 (Göttfert, Buchen, Germany). A temperature range from $140-160^{\circ} \mathrm{C}$ was selected for the measurements, the shear rate was varied between 1 and $8000 \mathrm{~s}^{-1}$. The solid loadings were set to 50 and 55 vol. \% which are equivalent to 77.4 and 80.9 wt.\%. Similar feedstocks with huge alumina amount (up to 58 vol.\%) were previously used in powder injection molding [34,35].

\subsection{Filament Extrusion and Printing via FFF}

All feedstocks were dried in a vacuum oven (Heraeus, Hanau, Germany) over night at $44{ }^{\circ} \mathrm{C}$ to remove adsorbed water, which is favorable due to the very hydrophilic binder properties. Finally, they were extruded to filaments applying a filament extruder (Noztek pro HT, Noztek, Shoreham, UK) at $110{ }^{\circ} \mathrm{C}$ (50 vol.\%) and $115^{\circ} \mathrm{C}$ (55 vol.\%), respectively. The selected nozzle diameter was $2.8 \mathrm{~mm}$. The resulting filaments were too brittle for winding; therefore, they were cut every $50 \mathrm{~cm}$ for direct feeding.

The filaments were used for 3D printing applying a modified FFF desktop printer (X350 pro, German RepRap, Feldkirchen, Germany). The conducted modifications mainly affect changes at the print head e.g., using a Titan extruder with a gear ratio of 3:1 allowing a more precise filament conveying [23]. The temperature of the polypropylene printing plate was set to $60{ }^{\circ} \mathrm{C}$; the printing temperature was $165^{\circ} \mathrm{C}$ with a printing speed of $10 \mathrm{~mm} / \mathrm{s}$. The nozzle was made from hardened steel due to the pronounced abrasion of the alumina feedstock; the nozzle's inner diameter was $0.25 \mathrm{~mm}$ enabling a printed layer thickness of around $0.1 \mathrm{~mm}$.

\subsection{Debinding and Sintering}

After printing and prior to sintering, all-organic moieties have to be removed by debinding either in a single thermal treatment or in a combination of solvent-assisted liquid removal (pre-debinding) of the low molecular PEG. The latter method was established for the fabrication of small and dense alumina and zirconia parts [33]. As shown there, a combination of solvent pre-debinding in water and thermal debinding was applied for removing the low molecular compound PEG. For debinding and sintering two chamber ovens (HT6/28 and RHF17/3, both from Carbolite, Neuhausen, Germany), were applied. The Archimedes method was used for the measurement of the sample densities.

\section{Results and Discussion}

\subsection{Material Selection}

The relevant properties of the used alumina particles have been reported earlier, the morphology obtained by SEM investigations shows mostly spherical nanosized primary particles, which are highly 
agglomerated (Figure 1) [23]. The measured specific surface area is relevant for the calculation of the surfactant amount needed; here an SA concentration of $3.3 \mathrm{mg} / \mathrm{m}^{2}$ related to the particle surface was selected guaranteeing a complete coverage of the alumina's surface enabling the formation of a homogeneous feedstock after compounding. The calculation of the feedstock composition is as follows, related to $100 \mathrm{~g}$ equivalent to $39.85 \mathrm{~cm}^{3}$ feedstock: The solid load, for example $50 \mathrm{vol} . \%$, defines the amount of SA due the above mentioned calculation ruled by the alumina's total surface area. Half of the remaining volume amount, here 50 vol.\%, is attributed to PEG being the low viscous binder component. The remaining fraction to $100 \%$ consists of the calculated amount of SA and PVB. As an example, 50 vol.\% alumina equals $77.5 \mathrm{wt} \% \%$ equals $77.5 \mathrm{~g}$ equals $915 \mathrm{~m}^{2}$ surface area in total. Under consideration of the given SA concentration, $3.3 \mathrm{~cm}^{3}(3.0 \mathrm{~g})$ surfactant is necessary. As described, $9.96 \mathrm{~cm}^{3}$ (12.2 g) equals the PEG amount, only $6.68 \mathrm{~cm}^{3}(7.3 \mathrm{~g})$ remains for PVB (all numbers are rounded). If necessary, this composition can be slightly modified if a lower viscous feedstock is needed (increasing PEG amount) or higher green stability (higher PVB amount) is targeted [34].



Figure 1. SEM-image of used nanosized alumina TM-DAR.

\subsection{Compounding and Rheological Characterization}

The use of an in-line torque recording mixer-kneader allows during compounding a validation of the homogeneity of the feedstock, derived from the fluctuation of the measured torque signal and the resulting final equilibrium value. The latter one gives a strong evidence for successful injection molding or here FFF-printing as a rule-of-thumb the equilibrium value should be below $10 \mathrm{Nm}$ for further processing. The compounding behavior of the investigated PEG/PVB/SA/alumina mixtures is shown in Figure 2. Three identical compositions were prepared showing the excellent repeatability of the compounding process even at a high solid load of 55 vol.\% (Figure 2a).

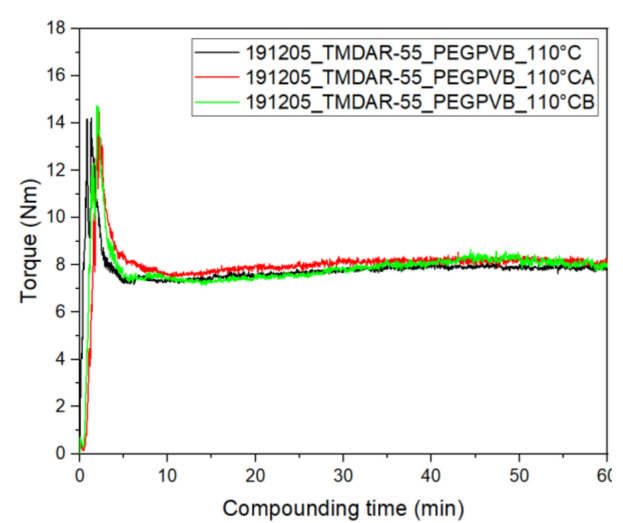

(a)

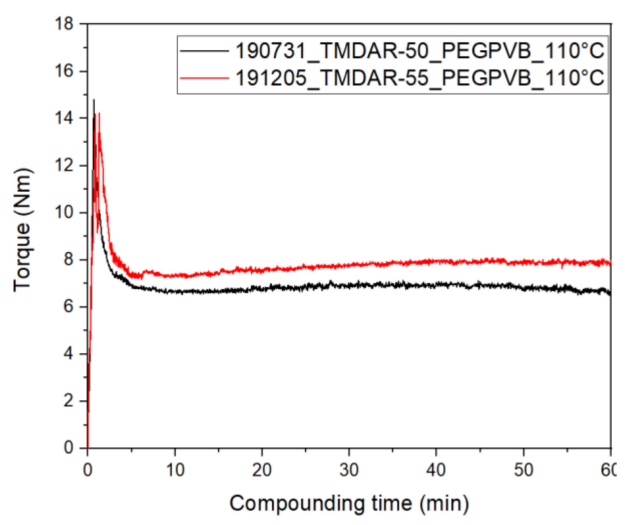

(b)

Figure 2. Compounding diagrams using the torque recording mixer/kneader of alumina in polyethyleneglycol (PEG)/polyvinylbutyral (PVB) $\left(\mathrm{T}=110^{\circ} \mathrm{C}, 30 \mathrm{rpm}\right)$; (a) Record of three different measurements with identical feedstocks (55 vol.\%); (b) Torque comparison at different solid loadings. 
Following the time proceeding torque values after $10 \mathrm{~min}$ almost equilibrium is reached, i.e., most agglomerates are destroyed and all particles are wetted by the surfactant $\mathrm{SA}$. Figure $2 \mathrm{~b}$ shows in addition the influence of the alumina load on the compounding process, the load reduction down to 50 vol.\% lowers the equilibrium torque value from approximately $8 \mathrm{Nm}$ down to $6.7 \mathrm{Nm}$ under identical processing conditions. A mixing temperature of $110^{\circ} \mathrm{C}$ was selected due to the pronounced thermal decomposition of PEG at elevated temperatures, for better comparison one compounding process was performed at $125{ }^{\circ} \mathrm{C}$ with an equilibrium torque value of $4.7 \mathrm{Nm}$ (50 vol.\% alumina, not shown here). A comparison with similar feedstock compositions delivers an interesting behavior: Wax/PE feedstocks with the same alumina and a solid load of $50 \mathrm{vol} . \%$ resulted in a final torque value around $5 \mathrm{Nm}\left(\sim 125^{\circ} \mathrm{C}\right)$, which is almost identical to the PEG/PVB based feedstock [23]. Applying the same binder composition, but a different alumina with larger average particle size and slight smaller specific surface area (Martoxid MR70, $d_{50}: 0.5-0.8 \mu \mathrm{m}, A_{\mathrm{BET}}=8.6 \mathrm{~m}^{2} / \mathrm{g}$ ), the equilibrium torque was approximately around $5 \mathrm{Nm}(50 \mathrm{vol} . \%)$ and $7 \mathrm{Nm}(55 \mathrm{vol} . \%)$, measured at $125^{\circ} \mathrm{C}$ [34]. As a result, under the given compounding conditions, the three different feedstocks behave quite similar demonstrating that the solid load is significantly below the critical filler load going along with a tremendous torque and viscosity increase.

High-pressure capillary rheometry allows for a more precise description of the feedstock flow behavior in the molten state, especially for the change of the viscosity with shear rate, denoted as pseudo plasticity, and solid load. Figure 3 describes the dependency of the melt viscosity as a function of shear rate, temperature, and solid load. An increase of the measuring temperature from 140 to $160^{\circ} \mathrm{C}$ cause only a small viscosity drop at higher shear rates, which is relevant for powder injection molding with its huge melt injection speed, but not significant for FFF with low shear rates during filament deposition (Figure 3a). In contrast, there is a pronounced impact of the solid load on the viscosity, especially at lower shear rates. In FFF, typical shear rates are in the range of $100 \mathrm{~s}^{-1}$, a rough estimation from Figure $3 b$ yields a significant higher viscosity for the feedstock with 55 vol.\% load (approximately $230 \mathrm{~Pa} \cdot \mathrm{s}$ ) in comparison to the one with 50 vol.\% (approx. $35 \mathrm{~Pa} \cdot \mathrm{s}$ ). The analogous wax/PE feedstock shows under identical conditions higher viscosity values around $270 \mathrm{~Pa} \cdot \mathrm{s}$ (50 vol.\%) and $350 \mathrm{~Pa} \cdot \mathrm{s}$ (55 vol.\%), both measured at a shear rate of $100 \mathrm{~s}^{-1}$ as well [23]. In the case of the identical binder but different alumina, a similar viscosity at $50 \mathrm{vol} \%$ (30 Pa.s) was found, but at higher solid loadings (55 vol.\%) the viscosity is increased (480 Pa.s) also [34]. Hence, it is recommended to use feedstocks with a moderate alumina load for FFF-printing allowing for parts with reduced number of defects.

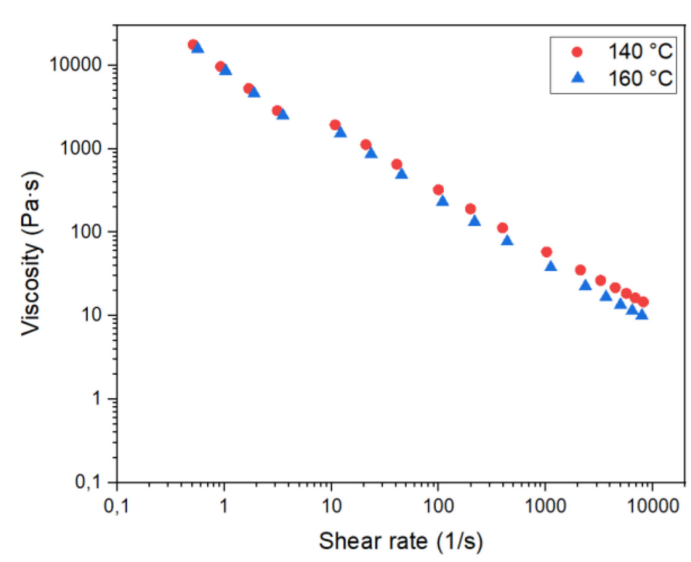

(a)

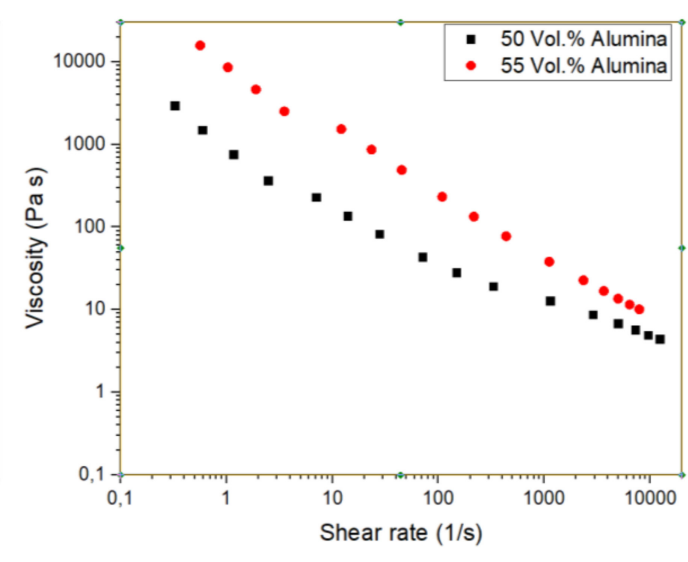

(b)

Figure 3. Rheological investigation on the alumina containing feedstocks: (a) Viscosity at two different temperatures (load: 55 vol.\%) and (b) Two different solid loadings (temperature: $160{ }^{\circ} \mathrm{C}$ ). 


\subsection{Filament Extrusion and Printing via FFF}

As described in Section 2.3, the different highly filled feedstocks were extruded to filaments. These were too brittle for winding, hence, they were placed directly in the printer's extruder hopper for feeding. Feedstock with 55 vol.\% were too brittle for extruding and printing, therefore all presented parts contain only 50 vol. \% alumina load. Specimen and different demonstrators were printed applying the above listed (Section 2.3) base printing parameters. Figure 4 shows two different types of printed test structures - massive type with complete infill (a) and fragile grids (b) - both typically denoted in ceramic processing as greenbodies. In the first case (Figure 4a), the printed V-structure indicates the printing direction. The greenbodies do not show any delamination and warpage after printing. Table 1 summarizes all relevant parameters for the new PEG/PVB based feedstock system in comparison to the established wax/PE-system reported in $[23,24]$. Two major information can be deduced from this table, first the printing parameters are quite similar, and second a reduced solid load in case of the PEG/PVP-mixture is necessary for successful printing. This comes directly from the viscosity measurements described earlier and causes a higher shrinkage during thermal post-processing due to the larger organic binder moiety.



(a)



(b)

Figure 4. Printed test structures. (a) Massive body (left: cuboid, right: disc) and (b) Open grid.

Table 1. Fused filament fabrication (FFF) Printing parameters for the new feedstock system.

\begin{tabular}{ccc}
\hline Item & PEG/PVP & Reference Wax/PE \\
\hline Solid & $\mathrm{Al}_{2} \mathrm{O}_{3}$ & $\mathrm{Al}_{2} \mathrm{O}_{3}$ \\
Solid load (vol. $\%)$ & 50 & 55 \\
Extrusion temperature $\left({ }^{\circ} \mathrm{C}\right)$ & $<170$ & $<170$ \\
Printing speed $(\mathrm{mm} / \mathrm{s})$ & 10 & 10 \\
Platform temperature $\left({ }^{\circ} \mathrm{C}\right)$ & 60 & 70 \\
Used nozzle diameter $(\mathrm{mm})$ & 0.25 & 0.25 \\
Printing quality & Very good & Very good \\
\hline
\end{tabular}

A more ambitious test structure was investigated estimating the achievable structural design quality and accuracy after printing. Figure 5a shows the CAD-drawing of the used clamping test structure. Beyond the standard geometric features (outer $\mathrm{x}, \mathrm{y}, \mathrm{z}$-dimensions), the asymmetric serrated profile is challenging for FFF-printing. Figure $5 b$, upper image, indicates the surface line scan directions (red and blue arrows) shown in Figure 6. Figure 5b, lower image, shows the printed greenbody and the related sintered alumina part. Figure 6a gives an overview about the surface topography measured of FFF-printed part, the individual printed layers can be easily seen, which is typical, especially in the case of FFF-printing, even if the smallest accessible printing nozzle is used. A closer look to the achievable surface quality via line scans is presented in Figure 6b. Figure 6b, upper image, delivers a scan along the red line in Figure 6a showing a repeatability of the sidewall position around $\pm 75 \mu \mathrm{m}$. The structure was placed on the printing platform with the largest surface area. The scan along the red line measures the layer-by-layer deviation during printing from the first printed layer to the last one (Figure 6b, upper image). The scan along the blue line represents the profile of one printed layer along the serrated 
structure (Figure 6b, lower image). It is obvious, that the pristine asymmetric shape of the serrated structure was not printed in a correct way.

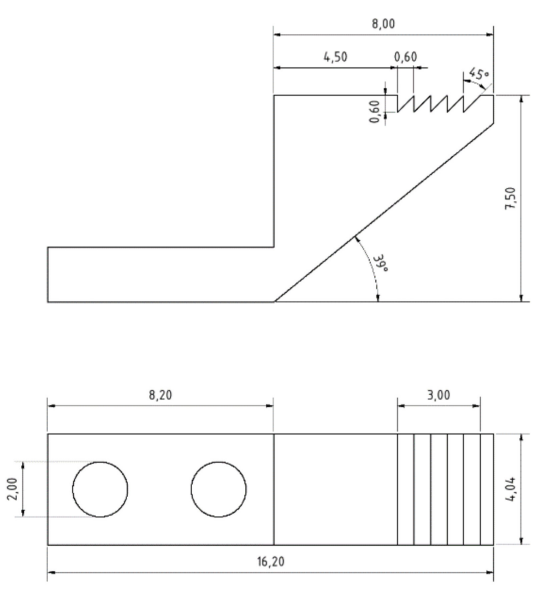

(a)
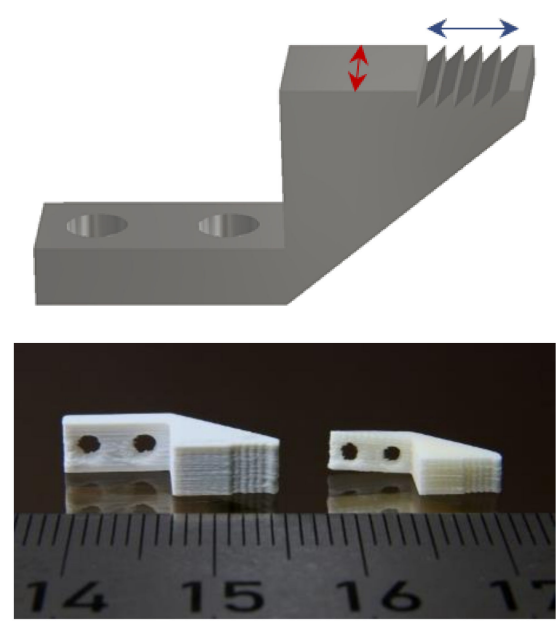

(b)

Figure 5. Clamping test structure: (a) 2D CAD-drawing and (b) Upper image: 3D CAD-drawing indicating scan directions, lower image: printed greenbody and sintered part.


(a)

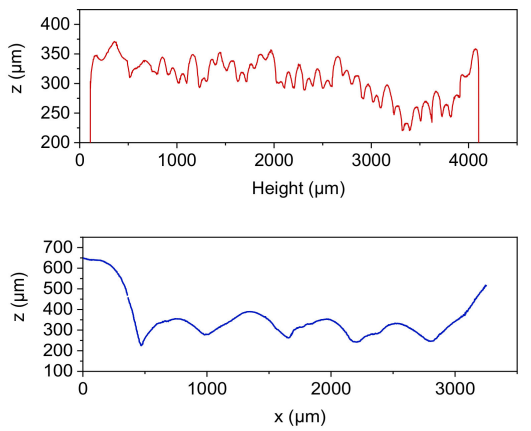

(b)

Figure 6. Surface topography analysis via white light interferometry: (a) 3D-surface scan and (b) upper image: profile of the structure's sidewall quality along the red arrow, lower image: profile of the serrated structure along the blue arrow.

\subsection{Debinding and Sintering}

With respect to dense and warpage-free ceramic parts, a solvent pre-debinding step for $24 \mathrm{~h}$ in water $\left(25^{\circ} \mathrm{C}\right)$ prior to thermal debinding and subsequent sintering was necessary. The following thermal treatment was performed very slowly not to activate any delamination between the individual printed layers due to evolved gaseous binder decomposition products (Table 2). As known from previous work, thermal debinding is completed around $500{ }^{\circ} \mathrm{C}$ [33]. With respect to the enhanced sinter activity of the TM-DAR alumina, a dilatometric investigation of a pressed specimen were done up to a temperature of $1600{ }^{\circ} \mathrm{C}$ [23] showing, that sintering started around $1000{ }^{\circ} \mathrm{C}$ and is finished at $1400^{\circ} \mathrm{C}$ when contraction due to sinter shrinkage ended. The fragile parts were sintered at a maximum temperature of $1400{ }^{\circ} \mathrm{C}$ following a simple thermal program (Table 3). The achieved part density measured by the Archimedes method is approximately $98 \%$ of the theoretical density. This is slightly below earlier values achieved, e.g., by reaction molding (99.2\% Th.) [36] or injection molding (99.7\% Th.) and can be attributed to voids generated during filament deposition during FFF-printing [23,24,39]. In case of the wax/PE-system a further load increase to 55 vol. \% yielded a density increase up to $99.6 \%$ Th. [24]. 
Table 2. Thermal debinding parameters.

\begin{tabular}{ccc}
\hline Step/Temperature $\left({ }^{\circ} \mathbf{C}\right)$ & Rate $\left({ }^{\circ} \mathbf{C} /\right.$ min) & Dwell Time @ Temperature (min) \\
\hline $25-120$ & 0.2 & 120 \\
180 & 0.2 & 120 \\
250 & 0.2 & 120 \\
500 & 0.2 & 60 \\
$500-25$ & n.a. & n.a. \\
\hline
\end{tabular}

Table 3. Sinter program.

\begin{tabular}{ccc}
\hline Step/Temperature $\left({ }^{\circ} \mathbf{C}\right)$ & Rate $\left({ }^{\circ} \mathbf{C}\right.$ min) & Dwell Time @ Temperature (min) \\
\hline $25-1400$ & 3 & 360 \\
$1400-25$ & 10 & 25 \\
\hline
\end{tabular}

In the following, more complex sintered test structures will be presented demonstrating the applicability of the new feedstock composition for the realization of alumina parts by FFF. Figure 7a shows one ring gear and structure details of the inner teeth, Figure $7 \mathrm{~b}$ two examples for different gear wheels. In both cases, a good surface quality can be seen.

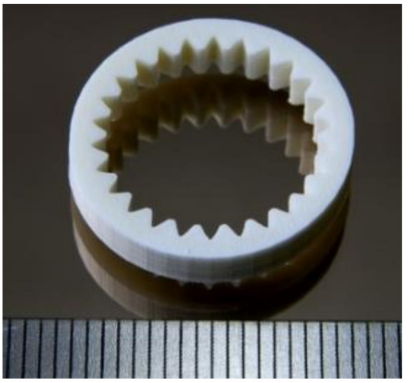

\subsection{Process Chain Evaluation}

The previous reported wax/polyethylene feedstock and resulting achievable part quality as well as process robustness serve as benchmark for the new PEG/PVB system. Table 4 compares the process chain for ceramic part fabrication for the new feedstock with the previous reported one $[23,24]$. All individual process steps can be done in comparable quality, only the maximum printable alumina load is reduced in case of the PEG/PVB mixture.

Table 4. Comparison two different feedstocks: overall process chain evaluation.

\begin{tabular}{ccc}
\hline Item & PEG/PVP ${ }^{1}$ & Reference Wax/PE ${ }^{\mathbf{1}}$ [23,24] \\
\hline Ceramic & $\mathrm{Al}_{2} \mathrm{O}_{3}$ & $\mathrm{Al}_{2} \mathrm{O}_{3}$ \\
Compounding & $\checkmark$ & $\checkmark$ \\
Filament extrusion & $\checkmark$ & $\checkmark$ \\
FFF printing & $\checkmark$ & 55 \\
Max. printable solid load (Vol.\%) & 50 & $\checkmark$ \\
Debinding & $\checkmark$ & $\checkmark$ \\
Sintering & $\checkmark$ & $99.4(50$ vol.\%), $99.6(55$ vol.\%) [24] \\
Max. ceramic part density (\% Th.) & $97.1 \pm 1.4$ & $20.4 \% \pm 1.4 \%$ (50 vol. $\%) ; 18.0 \% \pm 1.6 \%(55$ vol. $\%$ [24] \\
Average shrinkage & $20.75 \% \pm 0.8 \%$ & \\
\hline $1 \checkmark$ means process successfully established with good and reproducible quality.
\end{tabular}


In contrast to the wax/PE binder system the solvent-based debinding step was done in cold water instead of hot hexane $\left(50^{\circ} \mathrm{C}\right)$, which avoids the usage of the non-healthy and flammable hexane and simplifies the process chain significantly. Following the presented results, the new PEG/PVB binder system is a suitable alternative to the established ones.

\subsection{Comparison with Injection Molding}

A second benchmark is the comparison of FFF with injection molding applying an identical feedstock (composition, solid load, here 50 vol.\%). Due to technical reasons (number of produced parts for better statistics), the FFF-printed cuboid structure was compared with the injected molded (Battenfeld Microsystem 50, Kottingbrunn, Austria) disc structure. Both parts possess a similar thickness and volume. As expected and described in Section 3.2, injection molding with its high injection speed and pressure allows for higher ceramic densities around $100 \%$ of the theoretical density value (Table 5). The almost pressure-less FFF with the printing method related incorporation of voids during filament deposition first within the printed layer and second between the printed layers causes reduced density values around $97 \%$ Th., which are quite acceptable. Quite recently FFF-printing of a comparable system (50 vol.\% alumina), ethylene vinyl acetate (EVA) as binder, SA as surfactant) allowed for similar sinter densities around (sinter temperature $1600{ }^{\circ} \mathrm{C}$ ) $98 \%-99 \%$ Th. [25]. The listed shrinkage values (Table 5) must be explained in detail: The given deviation values do not represent the standard deviation, but the absolute deviation from the arithmetic mean value. In most of the cases, the values are identical, but in the case of the injection molded specimen a pronounced higher shrinkage value and deviation for the z-axis was observed. This influences the calculated average shrinkage value in an asymmetric manner.

Table 5. Comparison FFF-printed parts with injection molded ones.

\begin{tabular}{ccc}
\hline Item & FFF-Printed & Injection Molded \\
\hline Replicated part & Cuboid & Disc \\
Number of considered parts & 10 & 10 \\
Theoretical alumina density $\left(\mathrm{g} / \mathrm{cm}^{3}\right)$ & 3.97 & 3.97 \\
Average sinter density $(\% \mathrm{Th})$. & $97.1 \pm 1.4$ & 100 \\
Maximum part density $(\% \mathrm{Th})$. & 98.5 & 100 \\
Shrinkage x-axis & $21.0 \% \pm 0.5 \%$ & $20.0 \% \pm 0.3 \%$ \\
Shrinkage y-axis & $20.8 \% \pm 0.5 \%$ & $20.1 \% \pm 0.2 \%$. \\
Shrinkage z-axis & $20.5 \% \pm 0.8 \%$ & $21.7 \% \pm 1.1 \%$ \\
Average shrinkage & $20.75 \% \pm 0.8 \%$ & $20.6 \%+2.1 \%-0.9 \%$ \\
\hline
\end{tabular}

\section{Conclusions and Outlook}

A new two-component polar binder system, consisting of the low molecular weight polyethyleneglycol, which acts as plasticizer at higher temperatures, and polyvinylbutyral as backbone polymer, which allows for a certain mechanical stability in the green state after shaping, was used in sintered alumina part fabrication applying the FFF 3D printing method. As being established in ceramic injection molding, only small feedstock recipe adaptions with respect to the special requirements for FFF were necessary. Feedstocks with an alumina load up to 55 vol.\% could be compounded, but due to the large viscosity at printing temperature and brittle appearance a reduction down to $50 \mathrm{vol} . \%$ load was necessary for successful printing. After liquid pre-debinding and subsequent thermal post-treatment (debinding and sintering), dense and warpage-free alumina parts could be realized. It was possible to print and sinter, in addition to simple test specimen, even complex alumina parts like small gear wheels and gripper structures with challenging asymmetric structural details. Best achieved sinter densities were in the range of $98 \%$ of the theoretical value, which is quite comparable with data obtained from micro ceramic injection molding. The comparison of printed with similar parts, fabricated by micro ceramic injection molding, showed with respect to dimensional accuracy after printing no significant difference. Future work should consider alternative surfactants and the use of 
a PEG with a lower molecular weight for an enhanced plasticizing effect and a further increase of the accessible solid load reducing sinter shrinkage.

Author Contributions: Conceptualization, methodology, investigation, validation, and formal analysis, D.N. and T.H.; writing-review and editing, T.H.; supervision, project administration and funding acquisition, T.H. All authors have read and agreed to the published version of the manuscript.

Funding: This research was funded by Deutsche Forschungsgemeinschaft (DFG, grant number HA 1924/17-1). The article processing charge was funded by the DFG and the KIT in the funding program Open Access Publishing.

Acknowledgments: The authors kindly acknowledge Ralf Eickhoff (compounding) and Peter Holzer (injection molding) for experimental support.

Conflicts of Interest: The authors declare no conflict of interest. The funders had no role in the design of the study; in the collection, analyses, or interpretation of data; in the writing of the manuscript, or in the decision to publish the results.

\section{References}

1. Lin, L.; Kollipara, P.S.; Zheng, Y. Digital manufacturing of advanced materials: Challenges and perspective. Mater. Today 2019, 28, 49-62. [CrossRef] [PubMed]

2. Quanjin, M.; Rejab, M.R.M.; Idris, M.S.; Kumar, N.M.; Abdullah, M.H.; Reddy, G.R. Recent 3D and 4D intelligent printing technologies: A comparative review and future perspective. Proc. Comp. Sci. 2020, 167, 1210-1219. [CrossRef]

3. Chen, Z.; Li, Z.; Li, J.; Liu, C.; Lao, C.; Fu, Y.; Liu, C.; Li, Y.; Wang, P.; He, Y. 3D printing of ceramics: A review. J. Eur. Ceram. Soc. 2019, 39, 661-687. [CrossRef]

4. Ngo, T.D.; Kashani, A.; Imbalzano, G.; Nguyen, K.T.Q.; Hui, D. Additive manufacturing (3D printing): A review of materials, methods, applications and challenges. Compos. Part. B: Eng. 2018, 143, 172-196. [CrossRef]

5. Tofail, S.A.M.; Koumoulos, E.P.; Bandyopadhyay, A.; Bose, S.; O’Donoghue, L.; Charitidis, C. Additive manufacturing: Scientific and technological challenges, market uptake and opportunities. Mater. Today 2018, 21, 22-37. [CrossRef]

6. Singh, S.; Ramakrishna, S.; Singh, R. Material issues in additive manufacturing: A review. J. Manuf. Process. 2017, 25, 185-200. [CrossRef]

7. International Organization for Standardization. ISO/ASTM 52900:2018. Additive manufacturing-General principles-Terminology; International Organization for Standardization: Geneva, Switzerland; Beuth Publisher GmbH: Berlin, Germany, 2018.

8. Tiller, B.; Reid, A.; Zhu, B.; Guerreiro, J.; Domingo-Roca, R.; Curt Jackson, J.; Windmill, J.F.C. Piezoelectric microphone via a digital light processing 3D printing process. Mater. Des. 2019, 165, 107593. [CrossRef]

9. Gonzalez, G.; Chiappone, A.; Roppolo, I.; Fantino, E.; Bertana, V.; Perrucci, F.; Scaltrito, L.; Pirri, F.; Sangermano, M. Development of 3D printable formulations containing CNT with enhanced electrical properties. Polymer 2017, 109, 246-253. [CrossRef]

10. Khatri, B.; Lappe, K.; Habedank, M.; Mueller, T.; Megnin, C.; Hanemann, T. Fused Deposition Modeling of ABS-Barium Titanate Composites: A Simple Route towards Tailored Dielectric Devices. Polymers 2018, 10, 666. [CrossRef]

11. Hanemann, T.; Syperek, D.; Nötzel, D. 3D Printing of ABS Barium Ferrite Composites. Materials 2020, 13, 1481. [CrossRef]

12. Angelopoulos, P.M.; Samouhos, M.; Taxiarchou, M. Functional fillers in composite filaments for fused filament fabrication; a review. Mater. Today Proc. 2020. [CrossRef]

13. Mahmood, M.A.; Popescu, A.C.; Mihailescu, I.N. Metal Matrix Composites Synthesized by Laser-Melting Deposition: A Review. Materials 2020, 13, 2593. [CrossRef] [PubMed]

14. Herzog, D.; Seyda, V.; Wycisk, E.; Emmelmann, C. Additive manufacturing of metals. Acta Mater. 2016, 117, 371-392. [CrossRef]

15. Dowling, L.; Kennedy, J.; O'Shaughnessy, S.; Trimble, D. A review of critical repeatability and reproducibility issues in powder bed fusion. Mater. Des. 2020, 186, 108346. [CrossRef]

16. Lunetto, V.; Galati, M.; Settineri, L.; Iuliano, L. Unit process energy consumption analysis and models for Electron Beam Melting (EBM): Effects of process and part designs. Addit. Manuf. 2020, 33, 101115. [CrossRef] 
17. Zakeri, S.; Vippola, M.; Levänen, E. A comprehensive review of the photopolymerization of ceramic resins used in stereolithography. Addit. Manuf. 2020, 35, 101177. [CrossRef]

18. Hostaša, J.; Schwentenwein, M.; Toci, G.; Esposito, L.; Brouczek, D.; Piancastelli, A.; Pirri, A.; Patrizi, B.; Vannini, M.; Biasini, V. Transparent laser ceramics by stereolithography. Scr. Mater. 2020, 187, 194-196. [CrossRef]

19. Zhou, T.; Zhang, L.; Yao, Q.; Ma, Y.; Hou, C.; Sun, B.; Shao, C.; Gao, P.; Chen, H. SLA 3D printing of high quality spine shaped $\beta$-TCP bioceramics for the hard tissue repair applications. Ceram. Int. 2020, 46, 7609-7614. [CrossRef]

20. Xing, B.; Cao, C.; Zhao, W.; Shen, M.; Wang, C.; Zhao, Z. Dense 8 mol\% yttria-stabilized zirconia electrolyte by DLP stereolithography. J. Eur. Ceram. Soc. 2020, 40, 1418-1423. [CrossRef]

21. Scheithauer, U.; Abel, J.; Schwarzer, E.; Weingarten, S.; Kunz, W.; Moritz, T.; Klemm, H. CerAMfacturing of $\mathrm{Si}_{3} \mathrm{~N}_{4}$ Components. CeramApplications 2020, 8, 36-41.

22. Noetzel, D.; Eickhoff, R.; Hanemann, T. Fused Filament Fabrication of Small Ceramic Components. Materials 2018, 11, 1463. [CrossRef] [PubMed]

23. Noetzel, D.; Hanemann, T.; Eickhoff, R. Charakterisierung additiv gefertigter keramischer Bauteile via FFF-Verfahren. Keram. Z. 2019, 71, 56-61. [CrossRef]

24. Gorjan, L.; Galusca, C.; Sami, M.; Sebastian, T.; Clemens, F. Effect of stearic acid on rheological properties and printability of ethylene vinyl acetate based feedstocks for fused filament fabrication of alumina. Addit. Manuf. 2020, 36, 101391. [CrossRef]

25. Gorjan, L.; Tonello, R.; Sebastian, T.; Colombo, P.; Clemens, F. Fused deposition modeling of mullite structures from a preceramic polymer and $\gamma$-alumina. J. Eur. Ceram. Soc. 2019, 39, 2463-2471. [CrossRef]

26. Cano, S.; Lube, T.; Huber, P.; Gallego, A.; Naranjo, J.A.; Berges, C.; Schuschnigg, S.; Herranz, G.; Kukla, C.; Holzer, C.; et al. Influence of the Infill Orientation on the Properties of Zirconia Parts Produced by Fused Filament Fabrication. Materials 2020, 13, 3158. [CrossRef]

27. Cano, S.; Gonzalez-Gutierrez, J.; Sapkota, J.; Spoerk, M.; Arbeiter, F.; Schuschnigg, S.; Holzer, C.; Kukla, C. Additive manufacturing of zirconia parts by fused filament fabrication and solvent debinding: Selection of binder formulation. Addit. Manuf. 2019, 26, 117-128. [CrossRef]

28. Scheithauer, U.; Weingarten, S.; Johne, R.; Schwarzer, E.; Abel, J.; Richter, H.J.; Moritz, T.; Michaelis, A. Ceramic-Based 4D Components: Additive Manufacturing (AM) of Ceramic-Based Functionally Graded Materials (FGM) by Thermoplastic 3D Printing (T3DP). Materials 2017, 10, 1368. [CrossRef]

29. Vaidyanathan, R.; Walish, J.; Lombardi, J.L.; Kasichainula, S.; Calvert, P.; Cooper, K.C. The extrusion freeforming of functional ceramic prototypes. JOM 2000, 52, 34-37. [CrossRef]

30. Gonzalez-Gutierrez, J.; Cano, S.; Schuschnigg, S.; Kukla, C.; Sapkota, J.; Holzer, C. Additive Manufacturing of Metallic and Ceramic Components by the Material Extrusion of Highly-Filled Polymers: A Review and Future Perspectives. Materials 2018, 11, 840. [CrossRef]

31. Hanemann, T.; Weber, O. Polymethylmethacrylate/polyethyleneglycol-based partially water soluble binder system for micro ceramic injection moulding. Microsyst. Technol. 2014, 20, 51-58. [CrossRef]

32. Weber, O.; Hanemann, T. Green-conscious ceramic injection molding. In Advanced Processing and Manufacturing Technologies for Structural and Multifunctional Materials VI; Ihji, T., Singh, M., Halbig, M., Mathur, S., Eds.; John Wiley \& Sons: Hoboken, NJ, USA, 2013; pp. 63-71. [CrossRef]

33. Medesi, A.J.; Noetzel, D.; Hanemann, T. PVB/PEG-Based Feedstocks for Injection Molding of Alumina Microreactor Components. Materials 2019, 12, 1219. [CrossRef] [PubMed]

34. Medesi, A.J.; Nötzel, D.; Wohlgemuth, J.; Franzreb, M.; Hanemann, T. Ceramic Injection Moulding using 3D-Printed Mould Inserts. Ceram. Mod. Tech. 2019, 1, 104-110. [CrossRef]

35. Hanemann, T.; Honnef, K.; Hausselt, J. Process chain development for the rapid prototyping of microstructured polymer, ceramic and metal parts: Composite flow behaviour optimisation, replication via reaction moulding and thermal postprocessing. Int. J. Adv. Manuf. Technol. 2007, 33, 167-175. [CrossRef]

36. Piotter, V.; Hanemann, T.; Heldele, R.; Mueller, T.; Plewa, K.; Ruh, A. Metal and Ceramic Parts fabricated by Microminiature powder injection molding. Int. J. Powder Met.. 2010, 46, 21-28.

37. Antusch, S.; Hoffmann, J.; Klein, A.; Gunn, J.A.; Rieth, M. Processing of complex near-net-shaped tungsten parts by PIM. Nucl. Mater. Energy 2018, 16, 71-75. [CrossRef] 
38. Tülümen, M.; Hanemann, T.; Piotter, D.; Stenzel, D. Investigation of Feedstock Preparation for Injection Molding of Oxide-Oxide Ceramic Composites. J. Manuf. Mater. Process. 2019, 3, 9. [CrossRef]

39. Agarwala, M.K.; Jamalabad, V.R.; Langrana, N.A.; Safari, A.; Whalen, P.J.; Danforth, S.C. Structural quality of parts processed by fused deposition. Rapid Prototyp. J. 1996, 2, 4-19. [CrossRef]

(C) 2020 by the authors. Licensee MDPI, Basel, Switzerland. This article is an open access article distributed under the terms and conditions of the Creative Commons Attribution (CC BY) license (http://creativecommons.org/licenses/by/4.0/). 